\title{
Inglês como língua franca: desenvolvimentos recentes
}

\section{English as a lingua franca: recent developments}

Telma Gimenez *

Universidade Estadual de Londrina

Londrina - Paraná / Brasil

Michele Salles El Kadri**

Universidade Estadual de Londrina

Londrina - Paraná / Brasil

Luciana Cabrini Simões Calvo***

Universidade Estadual de Maringá

Maringá - Paraná / Brasil

Domingos Sávio Pimentel Siqueira****

Universidade Federal da Bahia

Salvador - Bahia / Brasil

Lucielen Porfirio*****

Universidade do Estado da Bahia

Alagoinhas - Bahia / Brasil

RESUMO: Em face da atual posição do inglês como uma língua franca global, este artigo tem como principal objetivo discutir os desenvolvimentos recentes dessa área, tomando como base os trabalhos apresentados durante a 7th International Conference of English as a Lingua Franca, realizada em Atenas, Grécia, em setembro de 2014. As reflexōes, aprofundadas nos tópicos i) teorizaçōes sobre inglês como língua franca (ILF), ii) ILF e formação de professores e iii) desenvolvimentos futuros, trazem um olhar analítico sobre os temas discutidos no evento. Espera-se que as informaçōes e reflexões aqui contempladas possam contribuir para o desenvolvimento de uma "curiosidade

*tgimenez@uel.br

**mielkadri@hotmail.com

***cabrinisimoes@gmail.com

****savio_siqueira@hotmail.com

*****lucielenporfirio@hotmail.com 
acadêmica" a respeito do paradigma ILF e para o engajamento com suas questôes e implicações.

PALAVRAS-CHAVE: inglês como língua franca; The 7th International Conference on English as a Lingua Franca; desenvolvimentos recentes.

\begin{abstract}
Given the current position of English as a global lingua franca, this article aims to discuss recent developments in this area of study, based on the papers presented at the 7th International Conference on English as a Lingua Franca, held in Athens, Greece, in September 2014. Under the topics i) theorizing about English as a lingua franca (ELF), ii) ELF and teacher education, and iii) future developments, we bring an analytical view on the issues presented at the event. We hope that the information and reflections included here may contribute to the development of an "academic curiosity" about the ELF paradigm as well as to further interest in its implications.
\end{abstract}

KEYWORDS: English as a lingua franca; The 7th International Conference on English as a Lingua Franca; recent developments.

\title{
Introdução
}

O acrônimo ELF (English as a lingua franca) - ou ILF, em português, tem sido adotado por um conjunto de pesquisadores que se alinham teoricamente à visão de que a língua inglesa é hoje utilizada majoritariamente em situações envolvendo falantes de diferentes línguas maternas e não exclusivamente em interações que tenham como interlocutores privilegiados os falantes nativos. Esses pesquisadores defendem que as interaçōes em inglês (nas quais são empregados recursos linguísticos e pragmáticos que tornam a referência a falantes nativos subalterna ao alcance satisfatório de seus propósitos comunicativos) configuram um novo fenômeno sociolinguístico que, certamente, nos levará "a uma compreensão [mais ampla] da natureza da linguagem assim como das convenções de descrição linguística"1(WIDDOWSON, 2012, p.6).

Embora em uma fase inicial os estudos que tomam como base a expansão mundial da língua inglesa tenham considerado a possibilidade de codificação dessas formas linguísticas como uma variedade, a exemplo do paradigma das variantes nativizadas dos World Englishes²(WEs), na

\footnotetext{
${ }^{1}$ Todas as citaçôes de obras em inglês têm tradução nossa.

${ }^{2}$ World Englishes é um paradigma de pesquisa associado especialmente ao linguista indiano radicado nos EUA, Braj B. Kachru, que busca descrever e analisar a variabilidade sociolinguística de formas do inglês nos países do chamado Círculo Externo (maioria
} 
atualidade, esse entendimento parece ser menos defendido. Na realidade, tem sido bem aceita a definição de que o ILF é "qualquer uso do inglês entre falantes de diferentes línguas maternas para quem ele é o meio de comunicação escolhido, e frequentemente, a única opção" (SEIDLHOFER, 2011, p.7).

Por esse prisma, ILF deveria ser "funcionalmente e não formalmente definido, [já que] não se trata de uma variedade de inglês, mas sim uma maneira variável de usá-lo" (SEIDLHOFER, 2011, p.77). Assim, a variabilidade do ILF é definida pelas diversas interações e diferentes usos da língua que podem ocorrer em inúmeras situações comunicativas. Contribuindo com tal entendimento, Berns (2011) também reconhece que 'língua franca' é o uso que se faz da língua e, dessa forma, não deve ser considerada uma variedade. De acordo com a pesquisadora, língua franca é um construto abstrato. Ela não é reconhecida de um modo particular que podemos afirmar que tenha determinada forma, pois será sempre diferente para aqueles que a usarem. Nas palavras de Berns,

[...] tenho dificuldade quando nós estendemos noções como a do inglês como língua internacional, inglês como língua franca e as equiparamos com variedades. Porque se nós dissermos "eu uso inglês como meio de instrução", nós não estamos falando sobre uma variedade em particular, nós estamos falando sobre o uso. (...) "língua franca", "inglês para comunicação internacional", estes são geralmente construtos que definem um uso da língua em termos mais amplos. (BERNS, 2011, p. 294)

Reconhece-se, desta forma, o caráter fluido e dinâmico das interações em ILF, com alto grau de imprevisibilidade, dado que os participantes podem ser falantes de quaisquer das mais de 6.000 línguas maternas existentes no mundo. Como se pode imaginar, sua codificação a partir de regularidades seria, no mínimo, uma tarefa gigantesca e desafiadora, para não dizer, quase impossível, devido ao seu uso tão diversificado em praticamente todos os cantos do planeta. Isto, contudo, parece não ter afugentado aqueles estudiosos que, auxiliados por diferentes projetos de construção de corpora

de ex-colônias britânicas), nos quais o inglês tem o papel de uma segunda língua oficial (MACKENZIE, 2014, p. 10). Na tentativa de categorização da expansão da LI no mundo, o linguista também propõe a denominação "Círculo Interno" para se referir aos países que usam a LI com língua materna e "Círculo em expansão" para designar os países que tomam o inglês como língua estrangeira. 
como o VOICE (Vienna-Oxford International Corpus of English) ou o ACE (Asian Corpus of English), têm buscado identificar características recorrentes nessas interações multilíngues (e.g. JENKINS, 2000; COGO, 2007; KIRKPATRICK, 2010; DEWEY, 2012; MAURANEN, 2012).

A conceituação do inglês que o afasta das normas do falante nativo tem colocado em xeque os construtos tradicionalmente empregados na linguística calcada exatamente em intuições de nativos ou aspectos puramente formais. Sendo assim, como caracterizar essa 'nova' e desafiadora situação sociolinguística? Que conceitos podem ser úteis para explicar de que forma a comunicação acontece (ou não) entre interagentes em contextos de ILF? Paralelamente aos desafios teóricos trazidos por dados colhidos etnograficamente, que requerem conceitos mais atuais do que seja língua em uso, isto é, que demandam tratamento multidisciplinar (tal como o que tem sido proposto em várias pesquisas em linguística aplicada), há que se pensar quais seriam as implicações desse novo enquadramento da língua inglesa para os processos de ensino-aprendizagem de inglês em diferentes contextos educacionais.

A relação entre o ensino e aprendizagem de língua inglesa e os estudos relativos ao ILF têm aos poucos se consolidado como importante área de pesquisa em linguística aplicada, o que pode ser verificado, entre outras iniciativas, a partir da criação de redes internacionais como a ELFReN ${ }^{3}$, concebida e liderada por Alessia Cogo (Londres, Inglaterra) e Marie-Luise Pitzl (Salzburg, Áustria), que assim apresentam o ILF:

Inglês como Língua Franca (ILF) é um campo de pesquisa em desenvolvimento que, na última década, tem encontrado seu lugar no interior da linguística aplicada. Ao longo desse tempo, temos visto um crescente número de publicaçōes e projetos de pesquisa em ILF, tais como o VOICE (Vienna-Oxford International Corpus of English) e o ELFA (English as a Lingua Franca in Academic Settings), a organização de conferências anuais sobre ILF e, mais recentemente, a criação do periódico JELF (Journal of English as a Lingua Franca) além de uma série de livros sobre ILF (Developments in English as a Lingua Franca) (COGO; PITZL, 2014).

${ }^{3}$ Disponível em <www.english-lingua-franca.org/about/elf-ren>. Acesso em: 20 nov 2014. 
Mais especificamente, as autoras argumentam ainda que a pesquisa em ILF se interessa principalmente pelo uso do inglês em situações interculturais onde falantes com diferentes backgrounds linguístico-culturais compartilham o inglês como língua comum de comunicação e como um recurso linguístico dinâmico e coconstruído. Também, a pesquisa em ILF tem sido conduzida em diferentes níveis, como na fonologia, léxico-gramática, pragmática e as interseções entre essas áreas. Diferentes domínios têm sido explorados por esses estudos, incluindo contextos acadêmicos e de negócios, e a pesquisa em ILF tem se expandido em outras dimensões, como, por exemplo, questôes relacionadas à atitude e identidade, aspectos (inter)culturais, implicações pedagógicas do fenômeno ILF, entre outros (COGO; PITZL, 2014).

Ainda segundo as autoras, com a quantidade cada vez maior de descrições empíricas disponíveis, algumas das questões mais prementes sobre o ILF se referem a aspectos de interesse da linguística aplicada, tais como o ensino de línguas e formação com base na comunicação, políticas linguísticas, conscientização sobre língua e multilinguismo. Outras temáticas se referem a questôes metodológicas, as quais se relacionam com abordagens quantitativa e qualitativa, assim como aspectos tecnológicos da aplicação da linguística de corpus (COGO; PITZL, 2014). Uma importante frente de trabalho futuro do ILF como um campo de alcance significativo na linguística aplicada parece ser a de receber colaboraçôes mais extensivas de pesquisadores de diferentes disciplinas, dentro e fora do campo da linguística (COGO; PITZL, 2014).

Embora essa rede seja constituída principalmente por pesquisadores baseados em sua maioria na Europa, o interesse pela área em diversos países tem crescido. No Brasil, por exemplo, alguns pesquisadores já fazem parte da ELF ReN, entre eles, os autores deste texto que também estão vinculados à Rede Brasileira de Estudos sobre Inglês como Língua Franca (cadastrada no $\mathrm{CNPq}$ ), grupo de pesquisa certificado que tem como objetivo construir entendimentos sobre essas formas de comunicação em inglês e suas implicações educacionais no contexto brasileiro, dialogando, principalmente, com aquelas realidades em que o inglês é estudado e aprendido como língua estrangeira (ILE). Estudos em nosso contexto têm sido realizados seguindo uma perspectiva de que o inglês é uma língua franca de alcance global (e.g. SIQUEIRA, 2010; EL KADRI, 2010, 2013; BORDINI; GIMENEZ, 2014; CALVO; EL KADRI; GIMENEZ, 2013, dentre outros). Essas pesquisas têm demonstrado que o ILF emerge como um conceito ainda 
pouco conhecido, muitas vezes tomado como um subtópico do paradigma World Englishes (WEs) ou considerado semelhante à proposta de "Inglês como língua internacional" (SMITH, 1976; MCKAY, 2002), na qual uma variedade de prestígio, em tese, é adotada internacionalmente, World Standard Spoken English (CRYSTAL, 1997).

Apesar de já fazer parte do senso comum a premissa de que o inglês é uma língua cada vez mais presente nas interaçōes entre falantes de diferentes línguas maternas nas mais diversas situaçôes comunicativas, há maneiras distintas de se representar essa realidade. $\mathrm{O}$ modo como os pesquisadores alinhados à terminologia ILF o fazem, constitui o objeto deste artigo. Dessa forma, aqui trataremos dos desenvolvimentos recentes na área, a partir de impressōes dos autores sobre os trabalhos apresentados durante a 7 th International Conference on English as a Lingua Franca (ELF 7), realizada em Atenas, Grécia, em setembro de 2014 (www.elf7.org). Não é nosso propósito, neste trabalho, ir além desse escopo, embora saibamos que discussões sobre inglês na contemporaneidade contemplam inúmeras outras perspectivas e relevantes frentes de discussão e investigação.

Com o tema central "Perspectivas Pedagógicas e Interdisciplinares" (Pedagogical and Interdisciplinary Perspectives), o evento contou com 160 trabalhos aceitos nas seguintes subáreas: Collecting ELF Corpora and Describing ELF, The Sociolinguistics of ELF, ELF and Multilingualism, ELF and Language Policy, ELF and Intercultural Communication, ELF and Language Education, Contact Languages and ELF, ELF Assessment and Evaluation, ELF Learners, ELF and Translation/Interpreting e ELF and Writing. Com o intuito de destacar alguns pontos discutidos durante a conferência e para efeitos de melhor organização do texto, dividiremos as seçōes nos seguintes tópicos: 1) Teorizações sobre ILF; 2) ILF e a formação de professores de inglês; 3) Desenvolvimentos futuros.

\section{Teorizações sobre ILF}

Uma das questôes centrais para os pesquisadores engajados em discussões sobre as consequências das novas territorialidades do inglês é, naturalmente, sua conceituação. Este é um terreno movediço e, portanto, muito complexo, uma vez que se configura como um campo em construção, desprovido de afirmações e assertivas que possam ser tomadas sem contestação (e.g. SWAN, 2012; O’REGAN, 2014; MACKENZIE, 2014, etc.). Entre diversas, uma das premissas aceitas é a de que o ILF é inerentemente 
variável (SEIDLHOFER, 2011; WIDDOWSON, 2012; 2014). Embora variabilidade seja um traço comum a todas as línguas naturais, a sua relativa estabilidade possibilita a codificação em forma de gramáticas e dicionários. Em ILF, no entanto, esta possibilidade não está tão clara, dado o caráter dinâmico das interaçôes em uma multiplicidade de contextos ${ }^{4}$.

Nesse pormenor, argumentam os pesquisadores de ILF, por exemplo, que "comunidade de fala" seria um conceito inadequado para referir-se aos falantes de ILF. Sendo assim, optam por "comunidade de prática", por esta ser constituída de participantes em arranjos provisórios, porém buscando cooperação e valendo-se de recursos comuns, como a língua e estratégias comunicativas ${ }^{5}$. Sob a perspectiva de comunidade de prática, a interação pela língua se configura à medida que práticas situadas são interconectadas e, nelas, e por meio delas, os indivíduos dão significado as suas participações. Em sua palestra "ELF and the pragmatics of language variation", Henry Widdowson argumentou que o desinteresse por ILF (apesar do reconhecimento de que se trata de uma característica da globalização $)^{7}$ pode derivar do fato de que as suas variações em relação a normas estabelecidas do inglês são tão aleatórias e irregulares que não podem ser caracterizadas como uma variedade, com sua comunidade distinta de usuários. E se não pode ser uma variedade, não se encaixaria no escopo da sociolinguística; se não puder ser uma variante dos "WEs", não serve como modelo estável para o ensino.

Para contrapor-se a essa visão, Widdowson (2014), então, postula que nos desvencilhemos desses preconceitos e consideremos o ILF sob uma perspectiva comunicativa, em termos da pragmática da variação. Ainda segundo o autor, o ILF não é uma variedade e é justamente por esse motivo que ele deveria ser objeto de discussão em estudos da sociolinguística

\footnotetext{
${ }^{4}$ Vários autores têm argumentado que a expansão do inglês pelo mundo provoca a necessidade de se repensar conceitos tradicionais da linguística, tais como linguagem e identidade (e.g. SEARGEANT, 2012; RAJAGOPALAN, 2011).

${ }^{5}$ Tem sido criticada a visão de que interagentes em ILF são sempre cooperativos. A respeito de uma possível romanticização do conceito de comunidade nos estudos em ILF, ver Park e Wee (2014).

${ }^{6}$ Disponível em <www.youtube.com/watch?v=EHr5rVyzzPM>. Acesso em: 20 nov. 2014.

${ }^{7}$ Nihalani (2010) elenca como os três elementos mais importantes do atual processo de globalização (1) os arrojados empreendedores globais, (2) a internet e (3) a língua inglesa.
} 
e particularmente relevante em pesquisas que consideram o ensinoaprendizagem da língua inglesa. Em outras palavras, o argumento de Widdowson (2014) é o de que o ILF se apresenta como nova área de pesquisa e que, por se tratar de um fenômeno relativamente recente, destaca-se exatamente por seu caráter inovador. Para o estudioso, a ideia de que língua é instável, dinâmica e variável de tal forma que os sistemas estáticos de regras não conseguem explicá-la, tem sido amplamente discutida dentro da área da linguística.

Nesse sentido, o conferencista, além de contestar a ideia de que a noção de língua como emergente seja algo inovador, defende que é preciso buscar as continuidades e retoma conceitos da sociolinguística laboviana (tais como a maneira pela qual a língua leva à realização de ações específicas) para explicar a variabilidade caracterizadora das interações em situação de língua franca na qual o inglês é empregado. Widdowson (2014) adota ainda o entendimento de que há legitimidade em regras variáveis, ou seja, o ILF não seria uma versão defeituosa do inglês, mas sim uma versão diferente deste, e, portanto, contrária à visão de privação verbal. Nesse escopo de pensamento, Widdowson (2014) afirma, então, que é possível comunicar-se sem demonstrar conformidade com o padrão.

É importante assinalar também que, embora o ILF não esteja em conformidade com regras de diferentes variedades (inclusive dos WEs), ainda assim, pode ser estudado em sua variação não sistemática. Enquanto no paradigma dos WEs a variação é válida somente se conectada com uma variedade, isto é, que tenha sido legitimada pela comunidade de falantes, no ILF a variação está em função do propósito comunicativo, ou seja, o objetivo é alcançar significação. O foco de ILF, é interessante que se esclareça, são os processos de variação, ao passo que os estudos de WEs seguem os preceitos da tradição sociolinguística de descrição de variedade, estabelecendo ligações entre comunidade e variação.

$\mathrm{Na}$ realidade, o ILF se preocupa com o que motiva o uso variável de recursos linguísticos para alcançarem-se os propósitos comunicativos em diferentes contextos. Posto de outra forma, o ILF se dedica ao estudo da pragmática da variação. Como se sabe, a pragmática estuda de que maneira o sentido é alcançado em comunidades com recursos compartilhados e, segundo essa área de pesquisa, a língua serve uma função de índice para uma realidade externa, assim como as regras da comunidade são construídas localmente. Como não há esse compartilhamento de regras nas interações 
em ILF, os interlocutores devem fazer uso de recursos linguísticos para coconstruir sentidos e alcançar efeitos pragmáticos. Endossando a visão funcionalista de que a forma deriva da função, Widdowson (2014) desenvolve ideias em torno do estudo pragmático da variação, com base no compartilhamento de significados. Assim, quanto mais familiar o contexto, menos língua se faz necessária e, portanto, as formas de ILF desempenham, em última instância, funçōes pragmáticas. No caso de interlocutores que não têm familiaridade entre si, as formas linguísticas empregadas cumpririam o papel de eliminar ambiguidades e garantir a comunicabilidade.

Ainda tomando a pragmática como arcabouço teórico, Widdowson (2014) faz o seguinte questionamento: Como explicar o princípio da cooperação de Grice $(1982)^{8}$ no contexto de ILF, uma vez que as convenções não são necessariamente partilhadas? Ou seja, como as pessoas cooperam em ILF se não podem se basear em regras culturais partilhadas? Para Widdowson (2014), isto se dá porque não se parte da forma para a função, mas ao contrário: a forma é determinada pela intencionalidade pragmática. Isto é, como aponta Cogo (2008, p.60), em ILF, “a forma parece vir depois da função, dando início a um fenômeno circular de variação e mudança”. Desse modo, as máximas de Grice (1982) se atrelam a um modelo cultural específico, não podendo servir para explicar o contexto de ILF. Nas interações em ILF, os interlocutores não podem depender de regras compartilhadas e, portanto, desenvolvem um denominador comum no momento em que a interação se desenvolve.

Do ponto de vista pedagógico, Widdowson argumenta ainda que uma abordagem verdadeiramente centrada no aluno levaria em conta a não conformidade com regras convencionadas para falantes nativos, ou seja, tomaria como foco central o alcance da comunicação e não a aderência a normas pré-estabelecidas em contextos de língua nativa, até porque essa obediência provocaria efeito contrário, ou seja, levaria a uma nãocomunicação. Isto se explicaria pelo fato de que os interagentes, no caso específico, não partilham da mesma linguacultura e, consequentemente,

${ }^{8}$ De acordo com Gomes (2011, p.12), o Princípio da Cooperação de Grice (1982) é composto por quatro máximas conversacionais: quantidade, qualidade, relevância e modo. A primeira trata da informação na medida necessária, nem mais nem menos informativa, a segunda diz respeito à veracidade da informação, a terceira refere-se à relevância da informação e, por último, a quarta enfoca a clareza das informaçōes, evitando-se com esta a prolixidade, ambiguidade, obscuridade e falta de ordem. 
constroem os efeitos pragmáticos na interação. Widdowson salienta que, apesar da relevância dos estudos de ILF para entendimento de como falantes da língua constroem significados a partir dos recursos linguísticos, o ensino do inglês continua atrelado à necessidade de conformidade a regras de falantes nativos, conforme demonstram a ênfase nos parâmetros do Quadro Europeu Comum de Referência para as Línguas: Aprendizagem, Ensino, Avaliação (sigla em inglês, CEFR) ${ }^{9}$ e os estudos de corpora envolvendo falantes nativos.

Sem dúvida alguma, a palestra de abertura de Henry Widdowson no ELF7 (2014) foi bastante provocadora no sentido de apresentar argumentos que salientam a relevância dos estudos de ILF, não só para as noções cristalizadas de variação nas línguas, mas também para os objetivos pedagógicos que, como sabemos, insistem na observância dos modelos ancorados na concepção do falante nativo.

A temática dos parâmetros definidos pela comunidade europeia e encapsulados no Quadro Comum Europeu também veio à tona na palestra proferida por Elana Shohamy ${ }^{10}$. A professora da Universidade de Telavive buscou abordar as relações possíveis entre ILF e a perspectiva crítica sobre testes, especialmente aqueles de validade e alcance internacionais. Segundo Seidlhofer (2011, p.185), mesmo adotando tal rótulo, esses testes "seguem uma orientação limitada do inglês como língua nativa". Ancorada no construto que chama de Avaliação Linguística Crítica (ALC - Critical Language Testing), a pesquisadora afirma que ILF e ALC ostentam grande capacidade de cooperação mútua, lembrando, de forma contundente, que testes de língua são encontros de alto risco e a maioria absoluta deles continua a avaliar o inglês a partir da variante nativa, recusando-se, peremptoriamente, a aceitar o fenômeno ILF (SHOHAMY, 2014). Nessa linha de pensamento, em texto de 2004, Shohamy já afirmava que

\footnotetext{
${ }^{9}$ Common European Framework for Reference for Languages: learning, teaching and assessment (CEFR). Documento elaborado em 2001 pelo Conselho da Europa como resultado de pesquisas e projetos sobre o ensino de línguas. Apesar de ter o contexto europeu como base, muitas das questões nele apresentadas são utilizadas por diversos países como instrumento de avaliação, independentemente da localização continental. Disponível em: <http://www.coe.int/t/dg4/linguistic/cadre1_en.asp>. Acesso em: 29 dez. 2014.

${ }^{10}$ Disponível em <www.youtube.com/watch?v=9TvrV7_-PZQ>. ELF7 Conference ElanaShohamy- Plenary Talk. Acesso em: 03 de nov 2014.
} 
os avaliadores linguísticos deveriam enxergar testes e exames não como eventos isolados, mas imbricados com variáveis psicológicas, sociais e políticas, cujos efeitos podem se estender a áreas como currículo, ética, classe social, política e conhecimento linguístico (SHOHAMY, 2004, p. 72-73).

Ainda, de acordo com a palestrante, a perspectiva crítica de avaliação implica questionar o poder de testes, examinando, entre outros aspectos, impacto, custo, ética e justiça. Após apresentar uma série de perguntas sobre testes que podem desvelar sua natureza e propósito (e.g. Os testes de lingua refletem as visóes mais atualizadas do que significa saber uma lingua em sociedades plurilingues? É justo comparar proficiência em lingua inglesa de aprendizes de segunda lingua com aquela de falantes nativos?), Shohamy argumentou que a área de avaliação e criação de exames e testes tem evoluído muito mais na questão de "como testar" de que "o que testar". Para a pesquisadora, os estudos em ILF podem contribuir em muito para novas definições exatamente do que testar, tanto por provocar redefinições do que seja língua quanto por ampliar sua diversidade de usos.

Os parâmetros atualmente empregados nesta área vão na contramão da ideia de língua como fluida, dinâmica, híbrida, em evolução constante, advogada pelo ILF. A adoção de padrões como aqueles delineados no Quadro Comum Europeu, na realidade, homogeneíza os falantes e penaliza os usuários que empregam formas híbridas, desenvolvem e fazem uso de estratégias de acomodação ou se apoiam em seus repertórios linguísticos para construírem e garantirem a comunicação.

O desafio, portanto, está em como convencer as instituições avaliadoras, professores, pais, diretores de escolas, a abraçarem a ideia de se conceberem testes empregando novos construtos que abarquem o atual panorama de interações globais, opondo-se, assim, à variedade monolíngue do nativo, ainda tão dominante e poderosa. Como assinala McNamara (2012), é mais que premente, neste momento, no processo de aprendizagem de segunda língua, se discutir e revisar a limitação dos modelos dominantes de competência comunicativa, assim como aqueles relacionados a sistemas de avaliação. Tal postura, sem sombra de dúvidas, provocará mudanças importantes na área, uma vez que, como nos lembra Lowenberg (2012),

ainda prevalece na avaliação da proficiência do inglês como língua internacional, a premissa de que o alvo universal da aprendizagem e do uso do inglês pelo mundo está restrito a uma série de normas do inglês 
padrão aceitas e seguidas por nativos de inglês com alta escolarização nos países do círculo central (LOWENBERG, 2012, p. 84).

Em suma, no tocante a teorizações sobre ILF, fica clara a necessidade de compreensão de que ILF não é uma variedade. A partir dessa premissa, a variação em ILF tem sido entendida a partir de outros construtos que não tomam a estabilidade como base. Ao invés de comunidade de fala, por exemplo, postula-se "comunidades de prática", sinalizando para sua instabilidade e para a prática da comunidade que se estabelece/se desenvolve a partir da interação dos membros em empreendimentos negociados conjuntamente, utilizando os seus repertórios compartilhados. O que se compartilha, neste caso, é a não natividade do inglês e os sentidos são construídos no momento da interação, tendo em vista a ausência de uma cultura partilhada que dispensa verbalização explícita. Em outras palavras, as formas emergentes surgem da necessidade de negociação dos sentidos e não preexistem ao momento interacional.

\section{ILF e a formação de professores de inglês}

A preocupação com as implicações pedagógicas dos estudos sobre ILF se revela no tema do evento e nas várias apresentações em sessões diversas. Durante o ELF7, tornou-se claro em muitos trabalhos a importância das discussóes do conceito para programas de formação docente e o desafio dos professores de língua inglesa de compreenderem e de articularem tais conceitos em suas práticas pedagógicas nas mais diferentes realidades.

Essa preocupação com as implicações pedagógicas sob uma perspectiva do ILF - embora já presente nas outras edições do evento (ELF 5, em Istambul, e ELF 6, em Roma, por exemplo), parece ter recebido uma posição de destaque no ELF 7: além das apresentações orais individuais, um colóquio com nomes influentes da área e uma palestra abordaram e discutiram a temática de forma bastante profícua e elucidativa, deixando clara, muitas vezes, a necessidade de se repensar a própria prática de formação de futuros professores de inglês.

Para começar, o colóquio ELF-Aware Teacher Education ${ }^{11}$, coordenado

\footnotetext{
${ }^{11}$ Participações de Yasemin Bayyurt (Bogaziçi University, Turquia), Nicos Sifakis (Helenic Open University, Grécia), Enric Llurda (Universitat de Lleida, Espanha), Martin Dewey (Kings' College London, Inglaterra) e Andrew Blair (University of Sussex, Inglaterra). O
} 
por Yasemin Bayyurt, por exemplo, foi dividido em duas sessões para tratar exclusivamente da formação de professores. Na primeira parte, as discussões retomaram aspectos teóricos como os já articulados na primeira seção deste texto. Já na segunda parte ${ }^{12}$, as discussões focalizaram considerações práticas do ILF na formação de professores. Assim, foram apresentados os resultados de um projeto (ELF-Ted Project $)^{13}$ destinado a professores que desejam conhecer mais sobre ILF e incorporar tais conceitos em sua prática de sala de aula. O projeto, envolvendo, inicialmente, professores e formadores da Turquia e Grécia, começa a despertar o interesse de profissionais de outros países, atraindo a atenção daqueles que, além de enxergarem-no como um excelente espaço de (re)qualificação, configura-se como uma oportunidade de intercâmbio de ideias e produção de conhecimento por parte de professores de inglês separados por distâncias físicas, mas muito próximos no tocante às realidades de ensino e aprendizagem de inglês com que se deparam diariamente.

Professores participantes do projeto apresentaram as atividades com base em premissas do ILF desenvolvidas em suas salas de aula. As propostas se fundamentaram em trabalhos de pesquisa-ação, com foco, principalmente, na oralidade. Imbuídos do propósito de transformar o contexto de ensino em que atuam, esses professores, contudo, demonstraram um certo distanciamento de uma das propostas da perspectiva do ILF (desenvolvimento da interculturalidade), concebendo, por exemplo, cultura de forma estereotipada, como algo vinculado a fatos ou costumes de países específicos (mesmo que tenham avançado no sentido de trazerem questôes de países não pertencentes ao círculo interno). Desse modo, nas atividades que foram compartilhadas, as questôes de cultura em sala de aula ainda apareceram atreladas a um tipo de comportamento geral de um determinado país ou comunidade no que diz respeito a pontos superficiais, tais como alimentação, festas típicas ou artefatos, o que, na nossa ótica, certamente, poderá vir a ser recontextualizado e redefinido à medida que estes docentes

colóquio pode ser acessado no endereço <www.youtube.com/watch?v=b4CrhYPtkrI>. ${ }^{12}$ Participações de professores da Turquia e da Grécia apresentando trabalhos no evento. ${ }^{13}$ De acordo com o site do projeto, o ELF TED objetiva implementar um quadro de referência para a formação de professores em ILF, conforme sugerido por Sifakis (2007). Disponível em: <http://www.teacherdevelopment.boun.edu.tr/index.html>. Acesso em: 12 out. 2014. 
avancem nas suas leituras, estudos e discussões sobre o ILF e suas implicações ideológicas e pedagógicas.

Outros aspectos como visões de mundo e crenças ou formas de alcançar inteligibilidade entre interlocutores parecem estar sendo deixados em segundo plano. Este aparenta ser um desafio a ser enfrentado, pois as aulas de línguas podem (e devem) servir para o desenvolvimento da competência intercultural, definida por Guilherme (2002, p. 297) como “a habilidade de interagir de maneira efetiva com pessoas oriundas de culturas que reconhecemos como diferentes da nossa".

Nesse sentido, é importante destacar que, em contextos de ILF, as questões culturais tornam-se mais explícitas do que em contextos "monolíngues" e, por isso mesmo, possibilitam a criação do que Kramsch (1993) chama de "esfera de interculturalidade". No entanto, diferentes perspectivas de cultura estão subjacentes às práticas apresentadas pelos professores. Isto, sem sombra de dúvidas, sugere a necessidade de se ampliar os entendimentos, mediante sugestôes práticas que permitam reconstruir sentidos para a relação língua/cultura em contexto de ILF.

Em outras palavras, aspectos cruciais inerentes à abordagem intercultural devem estar intimamente atrelados a um trabalho pedagógico que considere interações em ILF, e é fato que os professores só poderão entender o que isso significa a partir do momento em que tiverem a oportunidade de tentar, avaliar e redimensionar tais premissas. Portanto, repensar a proposição de atividades nas quais não se travam discussóes mais profundas sobre sentimentos e pontos de vista e propor açôes pedagógicas que propiciem a criação de um espaço de compreensão menos parcial entre a língua alvo e a língua nativa são questôes essenciais neste cenário e estas ações devem ser continuamente incentivadas para que professores de inglês nos mais variados contextos sejam empoderados nas suas práticas pedagógicas e também nas suas ações para além dos muros da escola.

Tratando ainda da formação de professores, a palestra de Nicos Sifakis (Helenic Open Univeristy), intitulada Towards a transformative ELF-aware education: challenges and opportunities for teaching, learning and teacher education ${ }^{14}$, apresentou entendimento do autor sobre o que vem a ser um professor consciente a respeito de ILF (an ELF-aware teacher). Conforme

\footnotetext{
${ }^{14}$ A palestra do Professor Nicos Sifakis na ELF7 Conference (Atenas, Grécia) está disponível no endereço eletrônico: <https://www.youtube.com/watch?v=ovr95tQX8AI)>.
} 
discutido em Sifakis (2014d), trata-se de uma proposta na qual os professores se familiarizam com as questóes relacionadas ao ILF e conectam o que entendem sobre a temática com suas próprias experiências como usuários e educadores, engajando-se, finalmente, em uma reorientação crítica de suas crenças e convicções sobre o ensino, integrando o que aprenderam sobre ILF em seu contexto de ensino de inglês como língua estrangeira (ILE).

Sifakis, em sua apresentação, aponta para o crescimento gradual de um discurso voltado para a mudança das práticas pedagógicas e das construçôes teóricas em vários estudos na área de ILF, como por exemplo, Widdowson (2012), que advoga pela mudança nas formas de pensar a descrição e o ensino da língua inglesa; Dewey (2012), que incentiva uma avaliação das práticas atuais de ensino e contextos de atuação; Jenkins, Cogo e Dewey (2011), que apontam para a necessidade de um engajamento maior entre a ideia de ILF e a sala de aula de línguas. Sifakis destaca, então, que uma vez que essa defesa pela mudança aparece de forma tão clara nas pesquisas em ILF, seria necessário também refletir sobre como tais mudanças podem ser efetivadas na prática diária de cada professor que atua nos mais diversos contextos e distintas culturas mundo afora.

Uma das questôes principais apontadas na palestra pelo educador grego é a necessidade de incentivar a reflexão constante por parte dos professores com o objetivo de: i) criar um suporte teórico do entendimento do que é ILF a partir de leituras e discussóes e ii) (re)pensar práticas pedagógicas em que tais aspectos possam ser desenvolvidos ou até mesmo questionados. $\mathrm{O}$ autor aponta, assim, tais fases em um estudo publicado em artigo recente para o Journal of English as a Lingua Franca (JELF):

Um referencial para a formação de professores preocupado com a conscientização sobre ILF precisa se ancorar em duas fases. Na primeira fase, professores são levados a ler trechos de pesquisas relacionadas ao ILF, assim como dos referenciais mais amplos de pesquisas da pedagogia crítica e da linguística aplicada pós-moderna; eles são levados a relacionar essas leituras a sua própria experiência e seu contexto por meio de perguntas estruturadas e abertas. Então, na segunda fase, professores se engajam em projetos de pesquisa-ação que utilizam aspectos relacionados ao ILF de maneiras mais apropriadas a seus contextos, 'reavaliam práticas em seus espaços de ação específicos de ensino, e incorporam mudanças na abordagem da maneira e até o ponto que seja adequado' (JENKINS et al 2011, p. 306). Em ambas as fases, os docentes se engajam numa viagem reflexiva que os leva a tornarem-se conscientes do desafio, e então transformam suas convicções mais profundas sobre o ensino e a 
comunicação em $E_{S O L}^{15}$ (SIFAKIS, 2014a, p. 328).

No fundo, a ideia principal de trabalhos como este parece ser o desenvolvimento profissional e pessoal de professores em exercício, (re) construindo seu próprio processo de conhecimento numa linha em que os conceitos e as formas de ensino não sejam impostos, mas sim pensados pelo próprio professor e, com certeza, por ele questionados com frequência.

Ainda no que diz respeito à formação de professores, salientamos o destaque para a necessidade de, a partir dessas reflexões, se desfazerem práticas históricas no ensino de línguas em que há um hábito já construído e arraigado de priorizar, entre outros aspectos, formas de ensino do inglês pautadas exclusivamente no modelo do falante nativo em detrimento do não nativo, práticas de ensino que primam por um ensino de estruturas linguísticas e que colocam a função comunicativa da língua em segundo plano. Tais hábitos, por enquanto, parecem manter-se não afetados por essas discussóes, conforme demonstrou Dewey (2014), a respeito de cursos de formação docente como CELTA, DELTA ${ }^{16}$, entre outros.

A oferta de um processo contínuo de participação e questionamentos é destacada no anteriormente citado projeto ELF TED de forma a fazer com que os professores se sintam, de fato, coautores do processo de criação e construção das práticas pedagógicas vigentes em seus contextos de atuação. Tal empreendimento, como se pode imaginar, demanda tempo para reflexão, discussão, interação, criação, aplicação e novas reflexões para que a mudança seja gradual, porém inevitável. Isso quer dizer que há um destaque para o fato de que mudanças nas maneiras de pensar o ensino de língua inglesa dentro de um contexto de ILF não acontecem (nem vão acontecer) de forma rápida, como num toque de mágica. Por conta disso, esforços são necessários para a criação paulatina de práticas transformadoras pelos próprios professores e, consequentemente, para a reflexão, avaliação e implementação das potenciais mudanças. Nesse sentido, ainda para Nicos Sifakis, é essencial que se realizem trabalhos em um ambiente em que o ILE e ILF não sejam colocados em oposição, mas em possível e salutar diálogo. Nas palavras do autor:

É equivocado e geralmente pouco prático considerar ILF e ILE como ‘e/ou'. Em países como a Grécia, muitos aprendizes em idade escolar

${ }^{15}$ ESOL - English for Speakers of Other Languages.

${ }^{16}$ Certificate/Diploma in Teaching English to Speakers of Other Languages. 
já têm alguma experiência em usar o inglês com outros falantes não nativos ao redor do mundo - eles fazem isso por meio de jogos on-line, por exemplo. Por essa perspectiva, esses aprendizes já são usuários de ILF. Mas isso não implica, de maneira alguma, que nós devemos substituir o currículo de ILE por um currículo de ILF. Tudo que devemos fazer é integrar e desenvolver uma mentalidade de consciência do ILF na maneira como ensinamos, considerando algumas das nossas ações como professores - o quanto nós corrigimos, por exemplo, ou até que ponto a nossa política de correção realmente se comunica com os aprendizes (SIFAKIS, 2014b, p. 14).

O que Sifakis destaca em sua palestra, portanto, é um trabalho que vise à junção da perspectiva de ILF à perspectiva de ILE, ou seja, ILE ao lado de ILF (EFL with ELF). Para ele, ao fim e ao cabo, o foco deve recair sobre o incentivo ao questionamento, à reflexão e a mudanças mais efetivas e constantes das práticas do dia a dia das salas de aula de ensino de línguas.

Embora essa proposta se apresente como realista em termos de promover uma transição menos traumática no ensino de inglês em contextos onde ele não é língua materna ou segunda língua,é preciso observar que as reflexões de natureza teórica que salientam interações em ILF como a face visível da variabilidade nas línguas, conforme apontado por Widdowson (2014) em sua palestra de abertura do evento em questão, requerem uma verdadeira 'revolução' no que concebemos por língua e comunicação eficiente. Se a noção de variedade, como Widdowson afirma, é apenas uma 'ficção conveniente', vale, então, perguntarmos: como promover um ensino que enfatize a necessidade de construção 'online' de sentidos? Como conciliar a aderência a normas de falantes nativos e a necessidade de justamente evitá-las, dado que os interlocutores que não partilham de regras comuns cooperam sob normas construídas no decorrer da interação e não a partir de regras estabelecidas pelas comunidades de falantes nativos?

Questionamentos à parte, se comparada às duas edições anteriores do evento, o ELF7, a partir dos debates e discussões ali conduzidos, pareceu demonstrar que as pesquisas em ILF têm avançado em termos de propostas práticas para a formação de professores. Até 2013, essas propostas ainda estavam centradas em conceitos mais abstratos, como, por exemplo, a adoção de uma pedagogia intercultural crítica, a necessidade de reconceituação dos cursos de formação e de um modelo que refletisse as realidades multilíngues e multiculturais da língua inglesa, entre outros (CALVO; EL KADRI; EL KADRI, 2014). Em congressos anteriores, propostas ainda iniciais foram 
apresentadas, tais como um modelo de consciência sobre ILF baseado na teoria transformativa de Mezirow (SIFAKIS, 2014d) e um trabalho focado em conscientização (LLURDA, 2014). Essas duas vertentes, no último evento, pareceram se delinear como propostas práticas de inserção do ILF em cursos de formação de professores.

Os trabalhos apresentados no ELF7, Atenas, pareceram sugerir discussões mais sistematizadas para a incorporação do ILF nos programas de formação/desenvolvimento de professores como um modo de promover oportunidades de fomento de novas atitudes e posturas. Essas possibilidades de incorporação de uma perspectiva de ILF em cursos de formação docente parecem estar baseadas em uma perspectiva cognitivista em que se salienta a necessidade de reflexão do professor sob as suas próprias condições de ensino, seu contexto local e as necessidades de seus aprendizes. O que parece estar subjacente às apresentações - conforme também apontado por Sifakis (2014d) - é o discurso da 'mudança'. Isto é, mudança nos modos estabelecidos de se pensar o ensino de línguas (WIDDOWSON, 2012), nas metodologias atuais (DEWEY, 2012), na forma de se conceber a pedagogia do ensino de línguas e de aliá-lo a uma pedagogia pós-falante nativo (BAKER, 2012), assim como crenças, atitudes e demais práticas (JENKINS; COGO; DEWEY, 2011).

Assim como Bayyurt e Sifakis (2014), LLurda (2014) também se preocupa com o tipo de conscientização necessária para os professores de língua inglesa na contemporaneidade. Segundo o pesquisador catalão, para que haja o desenvolvimento de uma consciência dos professores a respeito do ILF, é necessário que estes tenham a intenção de se tornarem usuários de ILF e notem as diferentes possibilidades de uso da língua, observem o fato de que ILF não possui formas específicas de uso linguístico e compreendam a sua natureza fluida. Llurda (2014) propõe um modelo de cinco estágios para a mudança de atitude na formação de professores. Segundo o autor, o Estágio 1 seria marcado pela exposição de situações realistas com exemplos de diversidade linguística e cultural; o Estágio 2 seria a análise de dados, mostrando a performance de profissionais não nativos (compreensão); o Estágio 3 envolveria a análise de exemplos de usos acadêmicos de ILF; o Estágio 4, os cenários prospectivos para o inglês internacional; e o Estágio 5 envolveria a reflexão de sua própria identidade de ensino, contexto e condições (compreensão) com foco no ideal (e, ao mesmo tempo, realista).

Embora tenhamos notado no ELF7 um maior destaque para as discussões relacionadas à formação de professores se comparados aos eventos 
anteriores, o que se observa é que, como as mudanças são lentas, ainda há muito o que pesquisar e discutir sobre a forma como professores de língua inglesa têm se posicionado diante dessa nova realidade de comunicação global. Consequentemente, é necessário que continuemos pensando nas práticas, reflexões e formas como as pesquisas desenvolvidas até agora podem ser melhoradas, questionadas ou trazer efetivas contribuições para a área de ensino de línguas vinculada à pesquisa em ILF.

Por outro lado, é preciso estarmos atentos à manutenção das hierarquias acadêmicas quando propomos conscientização ou mudanças nas práticas profissionais de educadores nas escolas. Como salienta Tupas (2014), a separação entre os que teorizam sobre ILF e os que estão na sala de aula, estejamos ou não conscientes de tal fato, pode ser perpetuada também por pesquisadores nesse campo, como a próxima seção sugere.

\section{Desenvolvimentos futuros}

Uma das questôes aparentemente consensuais nos trabalhos apresentados (BAKER, 2014; SIFAKIS, 2014a; 2014d; BLAIR, 2014; DEWEY, 2014) em relação aos desenvolvimentos futuros da pesquisa sobre o ILF é a necessidade de promoverem-se espaços para a conscientização de professores de língua inglesa que atuam nos mais variados contextos globais, para que estes repensem suas práticas e desenvolvam novas atitudes em relação a essa perspectiva que, queiram puristas ou não, carrega em si uma faceta libertária. Por exemplo, Blair (2014) enfatiza que ainda há muito ceticismo e resistência de professores em relação a novas ideias e que docentes experientes têm pouco ou quase nenhuma consciência de questões sociolinguísticas da língua em sua formação inicial. Do mesmo modo, Dewey (2014) aponta para a necessidade de uma maior compreensão e a adoção de atitudes mais proativas em relação ao ILF porque é absolutamente essencial para professores falantes não nativos de inglês tornarem-se profissionais conscientes deste construto, pois, segundo o autor, é a única maneira de se desviar a atenção do fardo pesado do irreal e idealístico falante nativo.

Assim como as palestras e colóquios, as comunicações orais presentes na programação do evento demonstraram que a grande maioria dos trabalhos teve como foco atitudes de professores de inglês em relação à perspectiva de ILF relacionada ao ensino, o que corrobora as conclusões de Calvo, El Kadri e El Kadri (2014), de que há um predomínio nos tipos de pesquisa que discutem justamente as atitudes dos professores em relação ao ILF. 
Entretanto, até o momento, são poucos os estudos que documentam e avaliam se e como o ILF vem sendo apresentado e tratado nos cursos de formação.

Baseados no pressuposto de que a experiência em ILF é um dos fatores que têm efeito positivo no desenvolvimento da consciência da natureza das interações nesta língua (BAKER, 2014) e que motiva os usuários de inglês como língua estrangeira (ILE) a resistir às asserçôes tradicionais de identificação com o falante nativo (KALOCSAI, 2009 apud BAKER, 2014), pesquisadores têm proposto a necessidade de se implementar o que chamam de "ELFing", ou seja, promover espaços para encontros interculturais entre alunos ou professores de diferentes países e culturas onde estes possam experimentar o pleno espaço de ILF. Isso se torna significativo no cenário de formação de professores porque (a) aprendizes que vivenciam ILF geralmente têm atitudes mais positivas (BAKER, 2014); (b) atitudes são aprendidas (GARRET, 2010 apud BAKER, 2014) e (c) as atitudes de participantes são relacionadas às suas experiências passadas de como as outras pessoas avaliam seu inglês (JENKINS, 2007 apud BAKER, 2014). É pautado neste reconhecimento da necessidade de promover oportunidade de desenvolvimento de novas atitudes que novas propostas de como propiciar a conscientização do ILF nos cursos de formação de professores têm sido elencadas, como, por exemplo, as propostas de Llurda (2014) e Sifakis (2014a), anteriormente descritas.

Também relacionado a essa questão das atitudes, o conceito de awareness (tomada de consciência), exposto por Llurda, parece ser adotado pelos palestrantes como ponto chave para a formação de professores de língua inglesa. A principal razão apontada do porquê de essa conscientização ser colocada como foco nos cursos de formação - tanto inicial quanto continuada - pode ser o empoderamento dos docentes no que diz respeito ao controle e à criação de suas próprias práticas educativas. Como podemos notar em uma entrevista conduzida durante o evento ${ }^{17}$, o argumento de pesquisadores tem sido que o ILF fornece aos professores um poder de controle das suas práticas, aumentando sua autoestima e, por isso, eles precisam se tornar conscientes da própria prática (BAYYURT, 2014; LLURDA, 2014). Isto porque o

\footnotetext{
${ }^{17}$ Entrevista realizada com Martin Dewey, Yasemin Bayyurt, Enric Llurda e Nicos Sifakis, e disponível em <http://elfpron.wordpress.com/2014/09/21/elf7-interviewgetting-started-with-elf>. Acesso em: 22 nov. 2014.
} 
ILF aumenta a confiança, evita frustrações e poupa energia dos docentes e também porque eles se dedicam à tarefa de adotar metas mais realistas para o ensino (SIFAKIS, 2014c). Além disso, ainda segundo Llurda (2014), o ILF foca no uso real da língua, permite aos professores transformarem sua própria condição e identidade (SIFAKIS, 2014c) e, principalmente, faz com que esses profissionais se sintam plenamente capazes de tomar decisóes sobre o currículo, o conteúdo e a avaliação, exigindo reflexões constantes tanto sobre a língua quanto sobre as formas de ensiná-la (DEWEY, 2014). No cenário internacional, essa questão da conscientização, provavelmente, está sendo desenvolvida, principalmente, com professores em fase de formação continuada.

Nesse sentido, podemos observar que o otimismo continua a prevalecer dentre os pesquisadores de contextos de ILF. Assim como os usuários são vistos como participantes ativos, negociadores e orientados para a solidariedade, também os educadores parecem nutrir visões mais positivas das suas repercussōes pedagógicas. Em um mundo onde professores tomam decisões sobre currículo e encontram recursos para apoiá-las, talvez isto seja possível. No mundo de uma grande parte dos professores que ensinam inglês as pressões são de outra natureza. Como salienta Tupas (2014),

[s] e começarmos a pesquisar na perspectiva de professores e alunos e suas salas de aula, onde e como colocamos a questão dos ingleses? Com esta linha de pesquisa, a sala de aula (aqui significando as vozes do "chão" ou da "prática") emerge como a fonte do conhecimento, ao invés de simplesmente como recipiente (via "implicaçôes") da argumentação e teorização sociolinguísticas. (TUPAS, 2014, p.162, grifos do autor)

Exemplos de outras forças que incidem sobre o trabalho do professor são os testes. Como nos apontou Shohamy (2014), enquanto o falante nativo for privilegiado e os testes tiverem o poder que têm sobre a vida das pessoas, dificilmente, um professor consciente poderá fazer muita diferença. Em uma perspectiva bem prática, o chamado de Canagarajah (2006) faz todo sentido:

Precisamos desenvolver instrumentos com imaginação e criatividade para avaliar a proficiência nas complexas necessidades comunicativas do inglês como língua franca. Esses instrumentos deveriam centrar-se na performance; deveriam enfatizar negociação social; e também demonstrar competência pragmática. Precisamos de testes que sejam interativos, colaborativos e performativos. Testes de múltipla escolha, com enfoque principalmente em gramática e vocabulários, ostentam uma utilidade 
limitada em contextos avaliativos do inglês como língua internacional (CANAGARAJAH, 2006, p. 240).

Testes e exames são instrumentos poderosos, os quais, de acordo com Shohamy (2004), precisam ser aplicados sob a égide de alguns princípios de inclusão importantes. Isto é, eles devem levar em consideração as vozes de diferentes grupos em sociedades multiculturais, precisam garantir aos avaliados um papel ativo e participativo, devem eliminar qualquer potencial de exclusão no processo avaliativo, em especial daqueles em condição de desvantagem, devem proteger o direito de cidadãos dos avaliados e, finalmente, em especial aqueles que desenvolvem ferramentas poderosas de poder, precisam assumir responsabilidade por suas consequências na aplicação dos testes. Ou seja, no tocante ao último princípio, complementa Shohamy (2004, p.79), "a implicação é a necessidade de aqueles envolvidos em avaliação assumirem responsabilidade pelos testes e pelos usos destes".

Fica claro no discurso de vários especialistas que a perspectiva do ILF é um campo fértil para que tais princípios sejam plenamente considerados e alcançados. A condição de língua global amealhada pela língua inglesa nos tempos contemporâneos, sem quaisquer sombras de dúvidas, nos abre enormes possibilidades de levarmos a cabo tais premissas. Na realidade, tratase de uma oportunidade ímpar de podermos alimentar a prática de sala de aula de língua inglesa com as descobertas das pesquisas sobre ILF.

Sob essa linha de pensamento, é preciso, então, que as pesquisas em ILF promovam essa interlocução, pois enquanto elas falharem em não dialogar com as instituições que podem legitimar essa perspectiva, uma avaliação crítica dos testes permanecerá indagando: "Até quando continuaremos avaliando para discriminar?” Como se vê, há muito ainda para se caminhar.

\section{Considerações finais}

Neste artigo, objetivamos tratar dos desenvolvimentos recentes na área de ILF a partir de nossas impressões sobre os trabalhos apresentados durante a 7th International Conference on English as a Lingua Franca, realizada na cidade de Atenas, Grécia. Sabedores das controvérsias que permeiam essa perspectiva e outras que questionam o conceito de "falante nativo" e de "norma padrão", entendemos que é um paradigma que oferece possibilidades de rupturas com conceitos tradicionalmente estabelecidos e que vão para muito além do Ensino de Língua Inglesa (ELI) propriamente dito. Diante do exposto, é 
importante refletir sobre que inglês queremos e que situações comunicativas em inglês (ou ingleses) nossos alunos encontrarão em um mundo no qual a homogeneidade e a heterogeneidade convivem no mesmo espaço.

Discussôes sobre perspectivas que relacionam ILF ao ensino ou à formação de professores de línguas ainda são incipientes em nosso contexto ${ }^{18}$, embora contemos com algumas produções articulando problematizações sobre o que seja língua e como sua ressignificação pode impactar o modo como ensinamos. Sendo assim, encampando uma visão otimista, é premissa nossa que a perspectiva do ILF oferece a possibilidade de não apenas pluralizar o inglês, mas de dar-lhe novos sentidos, novas formas, novas cores, novos contornos. Esperamos, assim, que este relato possa contribuir para o surgimento e o desenvolvimento de uma "curiosidade acadêmica" a seu respeito e, em última instância, provoque em alunos, professores e formadores de professores de língua inglesa, o engajamento com suas questóes e particularidades, ainda que, certamente, muito longe de respostas definitivas.

\section{Referências}

BAKER, W. From cultural awareness to intercultural awareness: culture in ELT. ELT Journal, 66(1), 62-70, 2012.

BAKER, W. Culture as discourse, practice, ideology. Palestra ministrada na $7^{\text {th }}$ international Conference of English as a Lingua Franca. Atenas, Grécia, 05 set. 2014. 2014.

BAYURT, Y. Elf7 Interview: getting started with ELF. 2014. Disponível em: http:// elfpron.wordpress.com/2014/09/21/elf7-interview-getting-started-with-elf/. Acesso em: 04 out. 2014.

BAYURT, Y.; SIFAKIS, N. Towards Elf-aware teacher education: lessons from a transformative self-education programme. Apresentação oral na $7^{\text {th }}$ International Conference of English as a Lingua Franca, Atenas, Grécia, 04 set. 2014

BERNS, M. Entrevista - English as a lingua franca: a conversation with Margie Berns. In: GIMENEZ, T.; CALVO, L.C.S.; EL KADRI, M.S. (Ed.) Inglês como lingual franca: ensino-aprendizagem e formação de professores. Campinas: Pontes Editores, 2011.

${ }^{18} \mathrm{O}$ V CLAFPL (Congresso Latino-Americano de Formação de Professores de Línguas), realizado em outubro de 2014, por exemplo, não teve nenhum trabalho que discutisse a formação de professores de língua inglesa nessa perspectiva. 
BLAIR, A. Standard Language Models, variable lingua franca goals: how can ELFaware teacher education square the circle? Apresentação oral na $7^{\text {th }}$ International Conference of English as a Lingua Franca, Atenas, Grécia, 04 set. 2014.

BORDINI, M; GIMENEZ, T. Estudos sobre inglês como língua franca no Brasil (2005-2012): uma metassíntese qualitativa. Signum: Estudos da linguagem, v.17, n.1, p. 10-43, 2014.

CALVO, L. C. S.; EL KADRI, M. S.; GIMENEZ, T. English as a lingua franca: a Brazilian perspective. In: VInternational Conference on English as a Lingua Franca - ELF 5, 2013, Istambul. ELF 5 Proceedings .Istambul: Bogazici University, p. $1-8,2013$.

CALVO, L. C. S.; EL KADRI; M.; EL KADRI, A. ELF in teacher education programs: mapping the proposal presented in ELF5 and ELF6. Apresentação oral na $7^{\text {th }}$ International Conference of English as a Lingua Franca, Atenas, Grécia, 06 set. 2014.

CANAGARAJAH, S. Changing communicative needs, revised assessment objectives: testing English as an international language.In: Language Assessment Quarterly, n.3, v. 3, 2006, p.229-242.

COGO, A. Intercultural communication in English as a Lingua Franca: a case study. Unpublished PhD Thesis. London: Kings College, 2007.

COGO, A. English as a lingua franca: form follows function. In: English Today, v. 24, n. 3, p. 58-61, 2008.

COGO, A.; PITZL, M. L. ELF Ren.ELF. 2014. Disponível em: <http://www. english-lingua-franca.org/about/elf-ren>. Acesso em: 25 set. 14.

CRYSTAL, D. English as a global Language. Cambridge. Cambridge University press, 1997.

DEWEY, M. Towards a post-normative approach: learning the pedagogy of ELF. In: Journal of English as a Lingua Franca, v. 1, n. 1, p. 141-170, 2012.

DEWEY, M. Language awareness and content knowledge among novice teachers: incorporating ELF in pre-service training. Apresentação oral na $7^{\text {th }}$ International Conference of English as a Lingua Franca, Atenas, Grécia, 04 set. 2014.

EL KADRI, M. S. Atitudes sobre o estatuto do inglês como Lingua franca em um curso de formação inicial de professores. 2010. 179f. Dissertação (Mestrado em Estudos da Linguagem)-Universidade Estadual de Londrina, Londrina, 2010.

EL KADRI, M. S., GIMENEZ, T. Formando professores para o contexto de inglês como língua franca.In: Acta Scientiarum, 2013, v. 35, n.2, p. 125-133.

GUILHERME, M. Critical citizens for an intercultural world: foreign language education as cultural politics. Clevedon, UK: Multilingual Matters, 2002. 
GIMENEZ, T.; CALVO, L. C. S.; EL KADRI, M. S. (Ed.) Inglês como língua franca: ensino-aprendizagem e formação de professores. Campinas: Pontes Editores, 2011. GOMES, K. M. S. O que se diz e o que se quer dizer: as entrelinhas da comunicação organizacional interna na perspectiva da teoria griceana. (Monografia). Curso de Bacharelado em Administração, UFPI, 2011, 65p.

GRICE, H. P. Lógica e Conversação. In: DASCAL, M. (Ed.). Fundamentos metodológicos da Linguística. Tradução de João Wanderley Geraldy. São Paulo: Global Universitária, 1982.

JENKINS, J. The phonology of English as an international language. Oxford, Oxford University Press, 2000.

JENKINS, J. Accommodating (to) ELF in the international university.In: Journal of Pragmatics, v. 13, n. 4, p. 926-936, March 2011.

JENKINS, J.; COGO, A.; DEWEY, M. Review of developments in research into English as a lingua franca. Language Teaching, v. 44, n. 3, p. $281-$ 315, July, 2011. Disponível em: < http://journals.cambridge.org/action/ displayAbstract?aid $=8271753>$.

KIRKPATRICK, A. English as a lingua franca in ASEAN. A multilingual model. Hong Kong: Univeristy of Hong Kong Press, 2010.

KRAMSCH, C. Context and culture in language teaching. New York, Oxford University Press, 1993.

LOWENBERG, P. Assessing proficiency in EIL. In: MATSUDA, A. (Ed.) Principles and practice of teaching English as an international language. Bristol (UK): Multilingual Matters, 2012. p.84-102.

LLURDA, E. Awareness, empowerment and overcoming (self)imposed limitations among English language teachers. Apresentação oral na $7^{\text {th }}$ International Conference of English as a Lingua Franca, Atenas, Grécia, 04 set. 2014.

LLURDA, E. Elf7 Interview: getting started with ELF. Disponível em: http:// elfpron.wordpress.com/2014/09/21/elf7-interview-getting-started-with-elf/ Acesso em: 21 out. $2014 \mathrm{~b}$.

MACKENZIE, I. English as a lingua franca - theorizing and teaching English. London: Routledge, 2014.

MAURANEN, A. Exploring ELF-Academic English shaped by non-native speakers. Cambridge: Cambridge University press, 2012.

MCKAY, S. L. Teaching English as an international language: Rethinking goals and approaches. Hong Kong: Oxford University Press, 2002.

MCNAMARA, T. English as a lingua franca: the challenge for language testing. In: Journal of English as a Lingua Franca, vol. 1, n. 1, p.199-202, 2012. 
NIHALANI, P. Globalization and International Intelligibility. In: SAXENA, M.; Omoniyi, T. (Ed.). Contending with Globalization in World Englishes. Bristol, UK: Multilingual Matters, p.23-44, 2010.

O'REGAN, J. English as a lingua franca: an immanent critique. Applied Linguistics, January 2014,(online) doi: 10.1093/applin/amt045.

PARK, J. S.; WEE, L. English as a lingua franca: lessons for language and mobility. In: Multilingual Margins, v.l, n.1, p. 53-73, 2014.

RAJAGOPALAN, R. The "Outer Circle' as a role model for the 'Expanding Circle'. In: English Today, v. 27, n.4, p. 58-63, 2011.

SEARGEANT, P. Exploring World Englishes: language in a global context. Abingdon: Routledge, 2012.

SEIDLHOFER, B. Understanding English as a Lingua Franca. Oxford: Oxford University Press, 2011.

SIFAKIS, N. C. The education of the teachers of English as a lingua franca: a transformative perspective. In: International Journal of Applied Linguistics, p. 355375, 2007.

SIFAKIS, N. ELF awareness as an opportunity for change: a transformative perspective for ESOL teacher education. In: Journal of English as Lingua Franca, v. 3, n.2, p. $317-335,2014 a$.

SIFAKIS, N. Interview: Nicos Sifakis talks about teaching English as a Lingua Franca. In: ELTNEWS, The Greek Monthly Newspaper for EFL, July/August, 2014b.

SIFAKIS, N. Elf7 Interview: getting started with ELF. 2014c. Disponível em: http:// elfpron.wordpress.com/2014/09/21/elf7-interview-getting-started-with-elf/. Acesso em: 21 out. 2014.

SIFAKIS, N. Towards a transformative ELF-Aware education: challenges and opportunities for teaching, learning and teacher education. Palestra proferida na $7^{\text {th }}$ International Conference of English as a lingua franca, Atenas Grécia, 06 set. $2014 d$.

SIQUEIRA, D. S. P. Inglês como língua internacional: por uma pedagogia intercultural crítica. In: SILVA, K. A. (Ed.) Ensinar e aprender linguas na contemporaneidade: linhas e entrelinhas. Campinas, SP: Pontes Editores, p. 25-52, 2010.

SHOHAMY, E. Assessment in multicultural societies: applying democratic principles and practices to language testing. In: NORTON, B.; TOOHEY, K. (ed.) Critical pedagogies and language learning. Cambridge: CUP, p.72-92, 2004. 
SHOHAMY, E. Critical Language Testing and English as a Lingua Franca. How one can help the other? Palestra proferida na $7^{\text {th }}$ International Conference of English as a lingua franca, Atenas Grécia, 05 set. 2014.

SMITH, L. English as an international auxiliary language. RELC Journal, vol. 7 , n.2, p.38-43, 1976.

SWAN, M. EFL and ELF are they really different? Journal of English as a Lingua Franca, v. 1, n. 2, p. 379-389, 2012.

TUPAS, R. The Unequal Production of Knowledge in the Sociolinguistics of Englishes. In: MARLINA, R.; GIRI, R. A. (ed.) The pedagogy of English as an international language - perspectives from scholars, teachers and students. Springer, p. 159-174, 2014.

WIDDOWSON, H. G. ELF and the inconvenience of established concepts. Journal of English as a Lingua Franca, v. 1, n.1, p. 5-26, 2012.

WIDDOWSON, H. G. - ELF and the Pragmatics of Language Variation. Palestra ministrada na $7^{\text {th }}$ InternationalConference of Lingua Franca, Atenas, Grécia, 04 set. 2014.

Data de submissão: 14/01/2015. Data de aprovação: 11/05/2015. 
